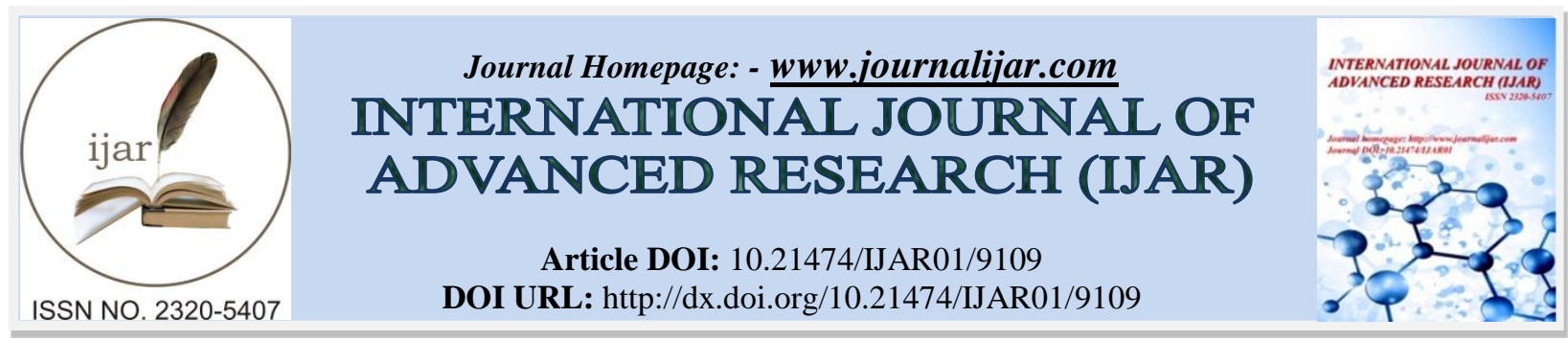

RESEARCH ARTICLE

\title{
IMPACT OF PROGNOSTIC VARIABLES ON THE SURVIVAL OUTCOME OF ORAL SQUAMOUS CELL CARCINOMA AND NASOPHARYNGEAL CARCINOMA PATIENTS AT KING FAHD MEDICAL CITY, RIYADH.
}

\section{Dr. Syed Sirajul Hassan, Dr. Abdulsalam Aljabab, Dr. Syed Hammad Ahsan and Prof. Hezekiah A. Mosadomi.}

\section{Manuscript Info}

Manuscript History

Received: 20 March 2019

Final Accepted: 22 April 2019

Published: May 2019

\section{Abstract}

\section{Introduction}

The reported morbidity of Oral Squamous Cell Carcinoma (OSCC) and Nasopharyngeal Carcinoma (NPC) throughout the world is high. The dilemma is that numerous patients develop OSCC and NPC who do not have a history of usage or exposure to the established risk factors.

Objectives

To extract socio-demographic, clinic pathological, histopathological and therapeutic data of OSCC / NPC patients from the online database software of King Fahd Medical City and Saudi Cancer Registry databases and to compare all of these variables with the "Overall Survival" of OSCC and NPC patients

Methods

The study was retrospective in nature. It comprised of a cohort of patients treated for Oral Squamous Cell Carcinoma (OSCC) / Nasopharyngeal Carcinoma (NPC) at King Fahd Medical City (KFMC). Frequency distribution, chi-square test and Kaplan-Meier survival analysis

Results

Following parameters had a statistically significant association with the overall survival of the subjects: Gender $(\mathrm{p}=0.022)$, age $(\mathrm{p}=0.001), \mathrm{T} 4$ sized tumor $(\mathrm{p}=0.007), \mathrm{N}$ status $(\mathrm{p}=0.037), \mathrm{M}$ status $(\mathrm{p}=0.001)$, histological grading $(\mathrm{p}=0.043)$, hemoglobin $(\mathrm{p}=0.011)$ and cancer being the cause of death $(\mathrm{p}=0.001)$

\section{Conclusion}

This study has identified clinic pathological parameters, which play an important role in determining the survival outcome of oral squamous cell carcinoma and nasopharyngeal carcinoma patients.

Copy Right, IJAR, 2019,. All rights reserved.

\section{Introduction:-}

The reported morbidity of Oral Squamous Cell Carcinoma (OSCC) and Nasopharyngeal Carcinoma (NPC) throughout the world is high. A leading journal in cancer research recorded 2,63,900 new cases and 1,28,000 deaths from OSCC worldwide in $2008^{1}$. The World Health Organization predicts further increase in the next few decades, as the prognosis largely remains unaltered despite the advancements in surgical, chemotherapeutic and radio therapeutic management of cancer ${ }^{2}$. To date; smoking, alcohol and chewable tobacco are considered as major risk 
factors of OSCC. In contrast, nasopharyngeal carcinoma (NPC) is comparatively rare in most parts of the world. Causative agents such as Epstein-Barr virus infection, vitamin $\mathrm{C}$ deficiency and dietary products containing $\mathrm{N}$ nitrosamines have been considered as potential causative factors of NPC. But the dilemma is that numerous patients develop OSCC and NPC who do not have a history of usage or exposure to the above mentioned risk factors. Surprisingly the outcome of some such tumors is unpredictable. These observations indicate that apart from the formerly identified risk factors other factors yet undetermined may also influence prognosis of OSCC and NPC, which can affect the survival outcome of such patients.

Anemia is commonly associated with cancer, about $50-60 \%$ of patients suffering from cancer develop anemia at variable stages of the disease ${ }^{3}$. It is likely that anemia also plays a deleterious role in progression of cancer. Anemia influences progression of cancer due to the effect of hypoxia on tumor cells which leads to decreased tumor oxygenation. Decreased tumor oxygenation in turn renders the hypoxic tumor cells resistant to oncological therapies specially radiotherapy ${ }^{4}$. Various studies have highlighted an association of anemia with progression of cancer. For instance a study on cervical carcinoma showed anemia as a strong prognostic factor for progression of cancer $\&$ demonstrated its correlation with patient survival ${ }^{5}$. Furthermore a study showed increased lymph node metastasis to be associated with increase in severity of anemia in OSCC patients ${ }^{6}$. Anemia itself is assessed on the level of Hemoglobin $(\mathrm{Hb})$ in patient's blood. Previous studies have shown that pre-treatment hemoglobin has been shown to be of clinical significance in evaluating progression of a disease ${ }^{7}$.

The purpose of this research project is to assess the role of various socio-demographic, clinic pathological, histopathological and therapeutic variables in the progression of OSCC and NPC by comparing the level of these independent variables with Overall Survival of OSCC and NPC patients.

\section{Aim Of Research Project}

- The aim of this research project is to assess the role of socio-demographic, clinicopathological, histopathological and therapeutic variables in determining the prognosis of oral squamous cell carcinoma and nasopharyngeal carcinoma

\section{Objectives Of Research Project}

- To extract preliminary data (socio-demographic, clinicopathological, histopathological and therapeutic data of OSCC / NPC patients) from the online database software of King Fahd Medical City and Saudi Cancer Registry databases

- To compare all of these variables "socio-demographic", "clinicopathological", "histopathological” with "Overall Survival" of OSCC and NPC patients to determine the impact of these independent variables on the prognosis of OSCC and NPC

\section{Materials \& Methods}

The research is retrospective and comprises a cohort of patients treated for Oral Squamous Cell Carcinoma (OSCC) / Nasopharyngeal Carcinoma (NPC) at King Fahd Medical City (KFMC) (a tertiary care hospital) located in Riyadh, Saudi Arabia. Furthermore, data will be extracted from the Dental medical records system.

The study subjects are patients who were treated for OSCC / NPC.

Sample Size Calculation with Statistical Justification:

The sample size is 420; a two-sided $95 \%$ confidence interval for a single proportion using the large sample normal approximation will extend (margin of error) 0.05 from the observed proportion for an expected proportion (OS) of $58.6 \%$.

\section{Inclusion Criteria:}

1. Patient diagnosed and treated for Oral Squamous Cell Carcinoma / Nasopharyngeal Carcinoma via Surgical Biopsy.

2. Patient with complete Socio-demographic, Clinical, Histological, Investigative and Therapeutic Record of Oral Squamous Cell Carcinoma/ Nasopharyngeal Carcinoma.

3. Patient on a 12 month follow up basis or on a follow up from time of diagnosis to recurrence or death.

Exclusion Criteria:

1. Patient without follows up data after initial diagnosis. 
2. Patient with previous malignancies or synchronous malignancies at time of diagnosis.

The Ethical Committees of Riyadh Colleges of Dentistry and Pharmacy and the RC-IRF committee of King Fahd Medical City for the study provided approval. Study requires extraction of data from the Electronic Health System in King Fahd Medical City and Saudi Cancer Registry. This data would be utilized for statistical analysis.

Data on the following variables was be utilized for statistical analysis:

- Age

- Gender

- Tobacco Usage

- Chief Complaint

- Duration Of Symptoms

- Location

- $\quad$ Size Of Primary Lesion (Cm)

- $\quad$ S Status

- N Status

- M Status

- Histological Grading

- Type Of Tumor

- Type Of Treatment

- Complications

- Recurrence

- Vital Status Disease

- Cause Of Death

- Hemoglobin (sub-categorized into separate categories titled "NORMAL Hb", "MILD ANEMIA" and "SEVERE ANEMIA" utilizing the hemoglobin ( $\mathrm{Hb}$ ) values defined by the World Health Organization (WHO), the patients were divided into a three groups: normal (female $\mathrm{Hb} \geq 12.0 \mathrm{~g} / \mathrm{dl}$; male $\mathrm{Hb} \geq 13.0 \mathrm{~g} / \mathrm{dl}$ ), mild anemia (female $\mathrm{Hb}=11.0-11.9 \mathrm{~g} / \mathrm{dl}$; male $\mathrm{Hb}=11.0-12.9 \mathrm{~g} / \mathrm{dl}$ ), and severe anemia (female \& male $\mathrm{Hb}<11.0 \mathrm{~g} / \mathrm{dl}$ )

- Initial Biopsy To Postop Survival

Data collection did not include collection of subject's name and every measure was taken to maintain subject's confidentiality and privacy.

\section{Statistical Analysis}

SPSS was utilized for statistical analysis. Descriptive statistics was performed to demonstrate the frequency distribution of all the measured variables. A univariate analysis (chi-square test) was performed to look for association(s) between all of the measured variables and the overall survival of the subjects. $\mathrm{P}$ value $<0.05$ was considered to be statistically significant. Kaplan-Meier Survival Analysis was performed in order to look for an association between the "hemoglobin" variable and "Dependent Variable" namely Overall Survival to evaluate the Survival Function $\mathrm{S}(\mathrm{t})$ and Hazard Function $(\lambda)$ of variable.

Results:-

Table 1: Frequency distribution of the studied parameters of the subjects

\begin{tabular}{|c|c|c|}
\hline & & $\mathrm{n}(\%)$ \\
\hline \multirow[t]{3}{*}{ Gender } & Female & $146(37.1)$ \\
\hline & Male & $248(62.9)$ \\
\hline & Total & $394(100.0)$ \\
\hline \multirow[t]{5}{*}{ Age (yr) } & $\leq 50$ & $194(46.6)$ \\
\hline & $>50$ & $222(53.4)$ \\
\hline & Total & $416(100.0)$ \\
\hline & $\min -\max$ & $10-89$ \\
\hline & Mean (SD) & $51.8(15.8)$ \\
\hline \multirow[t]{3}{*}{ Tobacco User } & No & $359(85.5)$ \\
\hline & Yes & $61(14.5)$ \\
\hline & Total & $420(100.0)$ \\
\hline
\end{tabular}




\begin{tabular}{|c|c|c|}
\hline \multirow{2}{*}{$\begin{array}{l}\text { Duration of } \\
\text { symptoms (month) }\end{array}$} & $\min -\max$ & $1-240$ \\
\hline & Mean (SD) & $15.3(37.3)$ \\
\hline \multirow[t]{5}{*}{ Location } & Left & $37(9.9)$ \\
\hline & Middle/anterior & $1(.3)$ \\
\hline & Right & $52(13.9)$ \\
\hline & Bilateral & $284(75.9)$ \\
\hline & Total & $374(100.0)$ \\
\hline \multirow[t]{11}{*}{ Chief complaint } & Exophytic lesion & $15(3.6)$ \\
\hline & Leukoplakia & $1(.2)$ \\
\hline & Other & $186(44.3)$ \\
\hline & Pain & $28(6.7)$ \\
\hline & Solid neck mass & $96(22.7$ \\
\hline & Ulcer & $34(8.1)$ \\
\hline & Headache & $10(2.4)$ \\
\hline & Difficulty in hearing & $12(2.7)$ \\
\hline & Epistaxis & $8(1.8)$ \\
\hline & Nasal obstruction & $37(8.7)$ \\
\hline & Total & $420(100.0)$ \\
\hline \multirow{2}{*}{$\begin{array}{l}\text { Size of primary } \\
\text { lesion }(\mathrm{cm})\end{array}$} & $\min -\max$ & $1-32$ \\
\hline & Mean (SD) & $4.2(4.0)$ \\
\hline \multirow[t]{4}{*}{ T_Size } & $<2 \mathrm{~cm}$ & $55(24.3)$ \\
\hline & $2-4 \mathrm{~cm}$ & $90(39.8)$ \\
\hline & $>4 \mathrm{~cm}$ & $81(35.8)$ \\
\hline & Total & $226(100.0)$ \\
\hline \multirow[t]{6}{*}{ T Status } & T1 & $55(16.3)$ \\
\hline & $\mathrm{T} 2$ & $89(26.3)$ \\
\hline & T3 & $75(22.2)$ \\
\hline & T4 & $111(32.8)$ \\
\hline & Tx & $8(2.4)$ \\
\hline & Total & $338(100.0)$ \\
\hline \multirow[t]{17}{*}{ T4 sized tumor } & Base of Skull & $42(37.8)$ \\
\hline & Base of Tongue & $16(14.4)$ \\
\hline & Alveolar bone & $6(5.4)$ \\
\hline & Intracranial region & $18(16.2)$ \\
\hline & Larynx & $32(28.8)$ \\
\hline & Pharynx & $22(19.8)$ \\
\hline & Palate & $6(5.4)$ \\
\hline & Ocular region & $9(8.1)$ \\
\hline & Adjacent Tissue & $4(3.6)$ \\
\hline & Brain & $1(0.9)$ \\
\hline & Mouth & $2(1.8)$ \\
\hline & Lung & $6(5.4)$ \\
\hline & Inner throat muscle & $5(4.5)$ \\
\hline & Mandible & $7(6.3)$ \\
\hline & Maxilla & $4(3.6)$ \\
\hline & Neck & $9(8.1)$ \\
\hline & Other skeletal region & $7(6.3)$ \\
\hline \multirow[t]{5}{*}{ N Status } & No & $93(28.0)$ \\
\hline & N1 & $94(28.3)$ \\
\hline & $\mathrm{N} 2$ & $111(33.4)$ \\
\hline & N3 & $34(10.2)$ \\
\hline & Total & $332(100.0)$ \\
\hline M Status & Missing & $85(20.2)$ \\
\hline
\end{tabular}




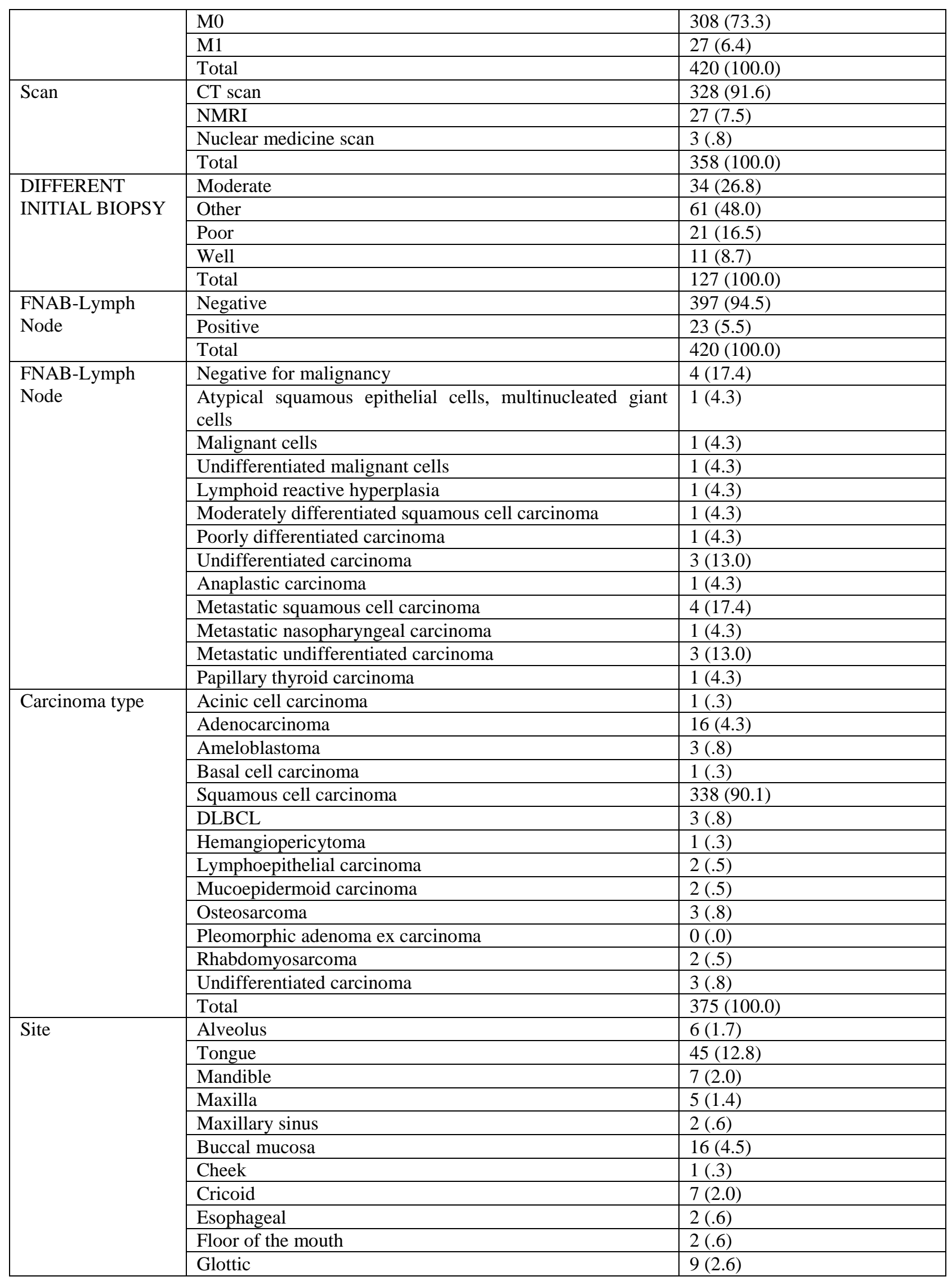




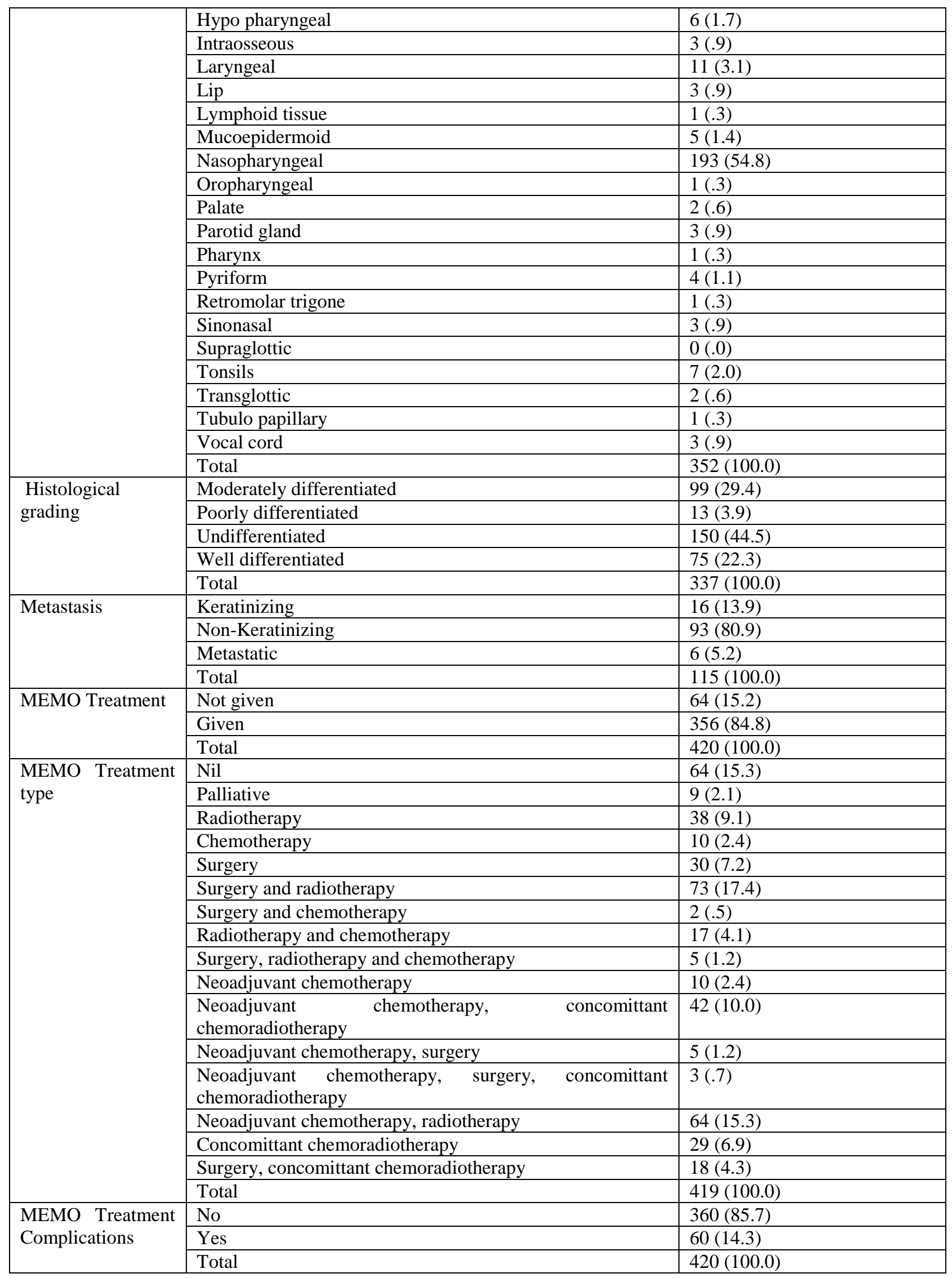




\begin{tabular}{|c|c|c|}
\hline \multirow{5}{*}{$\begin{array}{l}\text { MEMO Treatment } \\
\text { Complication type }\end{array}$} & Nil & $360(85.7)$ \\
\hline & Minor morbidity & $47(11.2)$ \\
\hline & Major morbidity & $12(2.9)$ \\
\hline & Mortality & $1(.2)$ \\
\hline & Total & $420(100.0)$ \\
\hline \multirow[t]{2}{*}{ Hemoglobin $(\mathrm{g} / \mathrm{dl})$} & $\min -\max$ & $7.1-17.8$ \\
\hline & Mean (SD) & $12.8(1.9)$ \\
\hline \multirow[t]{4}{*}{ Hemoglobin } & Normal & $252(69.0)$ \\
\hline & Mild anemia & $51(14.0)$ \\
\hline & Severe anemia & $62(17.0)$ \\
\hline & Total & $365(100.0)$ \\
\hline \multirow[t]{3}{*}{ Recurrence } & No & $390(92.9)$ \\
\hline & Yes & $30(7.1)$ \\
\hline & Total & $420(100.0)$ \\
\hline \multirow[t]{3}{*}{ Disease } & No & $131(83.4)$ \\
\hline & Yes & $26(16.6)$ \\
\hline & Total & $157(100.0)$ \\
\hline \multirow[t]{2}{*}{ Final outcome } & Survived & $323(76.9)$ \\
\hline & Died & $97(23.1)$ \\
\hline \multirow{3}{*}{$\begin{array}{l}\text { Cancer being the } \\
\text { cause of death }\end{array}$} & No & $376(89.5)$ \\
\hline & Yes & $44(10.5)$ \\
\hline & Total & $420(100.0)$ \\
\hline \multirow[t]{2}{*}{ Follow up (month) } & $\min -\max$ & $0-99$ \\
\hline & Mean (SD) & $44.2(22.5)$ \\
\hline
\end{tabular}

\begin{tabular}{|c|c|c|c|c|}
\hline & & Survived & Died & $\mathrm{p}$ value \\
\hline \multirow[t]{2}{*}{ Gender } & Female & $101(69.2)$ & $45(30.8)$ & \multirow[t]{2}{*}{0.022} \\
\hline & Male & $197(79.4)$ & $51(20.6)$ & \\
\hline \multirow[t]{2}{*}{ Age (yr) } & $\leq 50$ & $167(86.1)$ & $27(13.9)$ & \multirow[t]{2}{*}{$<0.001$} \\
\hline & $>50$ & $152(68.5)$ & $70(31.5)$ & \\
\hline \multirow[t]{2}{*}{ Tobacco User } & No & $279(77.7)$ & $80(22.3)$ & \multirow[t]{2}{*}{0.339} \\
\hline & Yes & $44(72.1)$ & $17(27.9)$ & \\
\hline \multirow[t]{4}{*}{ Location } & Left & $27(73.0)$ & $10(27.0)$ & \multirow[t]{4}{*}{0.817} \\
\hline & Middle/anterior & $1(100.0)$ & $0(.0)$ & \\
\hline & Right & $38(73.1)$ & $14(26.9)$ & \\
\hline & Bilateral & $219(77.1)$ & $65(22.9)$ & \\
\hline \multirow[t]{2}{*}{ T4 sized tumor } & No & $234(81.0)$ & $55(19.0)$ & \multirow[t]{2}{*}{0.007} \\
\hline & Yes & $76(68.5)$ & 35 (31.5) & \\
\hline \multirow[t]{3}{*}{ T_Size } & $<2 \mathrm{~cm}$ & $48(87.3)$ & $7(12.7)$ & \multirow[t]{3}{*}{0.067} \\
\hline & $2-4 \mathrm{~cm}$ & 68 (75.6) & $22(24.4)$ & \\
\hline & $>4 \mathrm{~cm}$ & $71(87.7)$ & $10(12.3)$ & \\
\hline \multirow[t]{4}{*}{ N_Status } & N0 & $80(86.0)$ & $13(14.0)$ & \multirow[t]{4}{*}{0.037} \\
\hline & N1 & 77 (81.9) & $17(18.1)$ & \\
\hline & N2 & $79(71.2)$ & $32(28.8)$ & \\
\hline & N3 & $24(70.6)$ & $10(29.4)$ & \\
\hline \multirow[t]{3}{*}{ M_Status } & Missing & $61(71.8)$ & $24(28.2)$ & \multirow[t]{3}{*}{0.001} \\
\hline & M0 & $248(80.5)$ & $60(19.5)$ & \\
\hline & M1 & $14(51.9)$ & $13(48.1)$ & \\
\hline \multirow[t]{3}{*}{ Scan } & CT scan & $243(74.1)$ & 85 (25.9) & \multirow[t]{3}{*}{0.419} \\
\hline & NMRI & $22(81.5)$ & $5(18.5)$ & \\
\hline & Nuclear medicine scan & $3(100.0)$ & $0(.0)$ & \\
\hline DIFFERENT & Moderate & $27(79.4)$ & $7(20.6)$ & 0.825 \\
\hline
\end{tabular}




\begin{tabular}{|c|c|c|c|c|}
\hline \multirow[t]{3}{*}{ BIOPSY } & Other & $44(72.1)$ & $17(27.9)$ & \\
\hline & Poor & $16(76.2)$ & $5(23.8)$ & \\
\hline & Well & $9(81.8)$ & $2(18.2)$ & \\
\hline \multirow[t]{2}{*}{ FNAB-Lymph Node } & Negative & $305(76.8)$ & $92(23.2)$ & \multirow[t]{2}{*}{0.874} \\
\hline & Positive & $18(78.3)$ & $5(21.7)$ & \\
\hline \multirow[t]{4}{*}{ Histological grading } & Moderately differentiated & $64(64.6)$ & $35(35.4)$ & \multirow[t]{4}{*}{0.043} \\
\hline & Poorly differentiated & $8(61.5)$ & $5(38.5)$ & \\
\hline & Undifferentiated & $119(79.3)$ & $31(20.7)$ & \\
\hline & Well differentiated & $58(77.3)$ & $17(22.7)$ & \\
\hline \multirow[t]{3}{*}{ Metastasis } & Keratinizing & $12(75.0)$ & $4(25.0)$ & \multirow[t]{3}{*}{0.809} \\
\hline & Non-Keratinizing & $76(81.7)$ & $17(18.3)$ & \\
\hline & Metastatic & $5(83.3)$ & $1(16.7)$ & \\
\hline \multirow[t]{2}{*}{ MEMO Treatment } & Not given & $46(71.9)$ & $18(28.1)$ & \multirow[t]{2}{*}{0.3} \\
\hline & Given & $277(77.8)$ & $79(22.2)$ & \\
\hline \multirow{2}{*}{$\begin{array}{ll}\text { MEMO } & \text { Treatment } \\
\text { Complications } & \\
\end{array}$} & No & 277 (76.9) & $83(23.1)$ & \multirow[t]{2}{*}{0.962} \\
\hline & Yes & $46(76.7)$ & $14(23.3)$ & \\
\hline \multirow[t]{3}{*}{ Hemoglobin } & Normal & $201(79.8)$ & $51(20.2)$ & \multirow[t]{3}{*}{0.011} \\
\hline & Mild anemia & 35 (68.6) & $16(31.4)$ & \\
\hline & Severe anemia & $39(62.9)$ & $23(37.1)$ & \\
\hline \multirow[t]{2}{*}{ Recurrence } & No & $304(77.9)$ & $86(22.1)$ & \multirow[t]{2}{*}{0.067} \\
\hline & Yes & $19(63.3)$ & $11(36.7)$ & \\
\hline \multirow[t]{2}{*}{ Disease } & No & $127(96.9)$ & $4(3.1)$ & \multirow[t]{2}{*}{0.367} \\
\hline & Yes & $26(100.0)$ & $0(.0)$ & \\
\hline \multirow{2}{*}{$\begin{array}{l}\text { Cancer being the cause of } \\
\text { death }\end{array}$} & No & $322(85.6)$ & $54(14.4)$ & \multirow[t]{2}{*}{$<0.001$} \\
\hline & Yes & $1(2.3)$ & $43(97.7)$ & \\
\hline
\end{tabular}

Figure 1. Kaplan-Meier curves of overall survival for patients with normal hemoglobin, mild anemia and severe anemia.

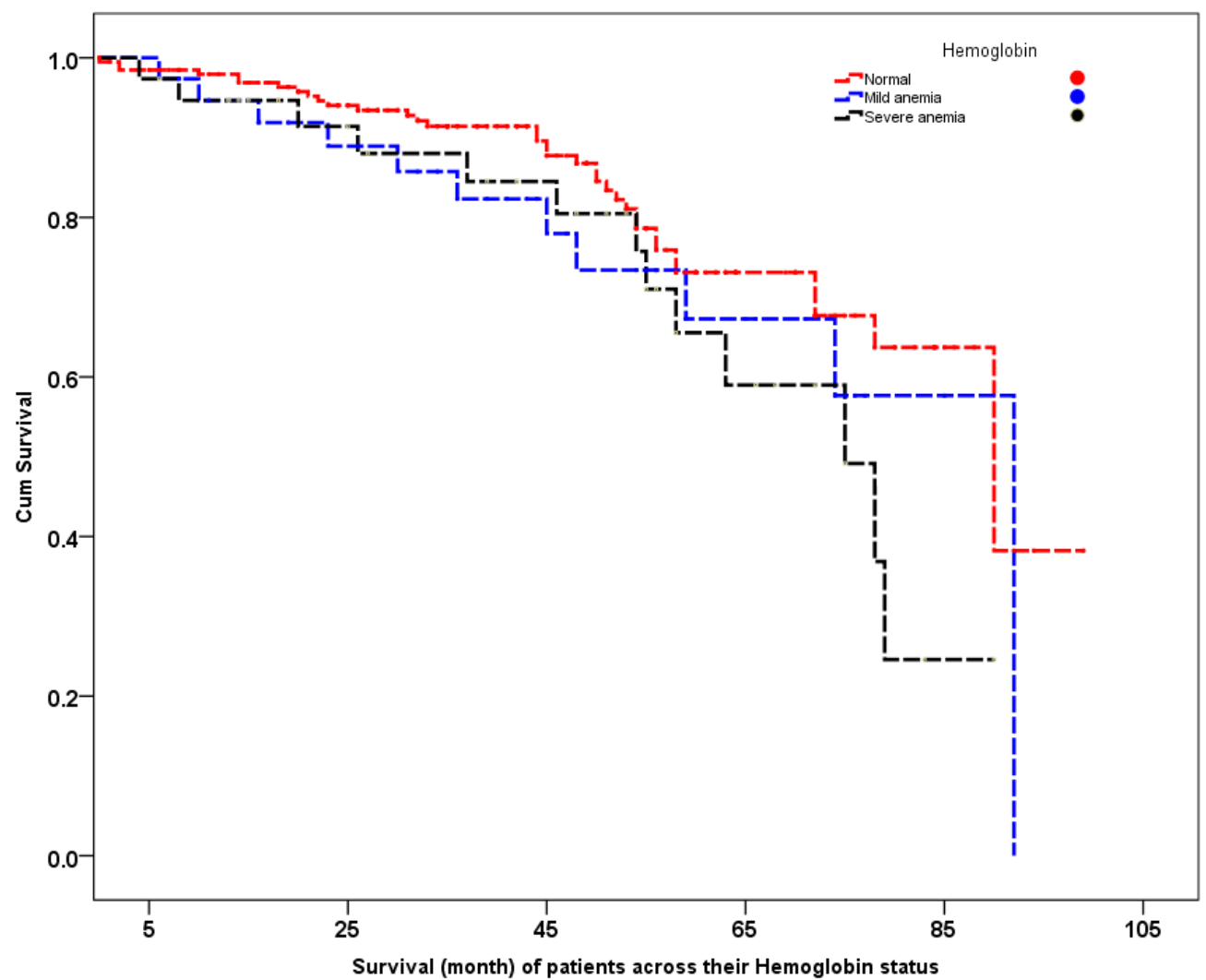




\begin{tabular}{|l|l|l|l|l|}
\hline Table 3: Means for Survival Time \\
\hline \multirow{2}{*}{ Hemoglobin } & Mean & \multicolumn{4}{|l|}{} \\
\cline { 2 - 5 } & Estimate & Std. Error & $95 \%$ Confidence Interval \\
\cline { 3 - 5 } & & & Lower Bound & Upper Bound \\
\hline Normal & 78.887 & 2.744 & 73.509 & 84.264 \\
\hline Mild anemia & 71.666 & 5.551 & 60.786 & 75.546 \\
\hline Severe anemia & 66.252 & 4.660 & 57.119 & 80.345 \\
\hline Overall & 75.859 & 2.289 & 71.372 & \\
\hline
\end{tabular}

\section{Discussion:-}

Our study comprised of a total of 420 subjects. Males comprised of $63 \%$ of the subjects, while, approximately $54 \%$ of the subjects were more than 50 years of age. Only $14.5 \%$ of the subjects were tobacco users. The duration of symptoms, on an average, was around 15 months. Only one subject presented with leukoplakia as a chief complaint, while, fifteen presented with an exophytic growth, thirty four presented with an ulcer and ninety six presented with a solid neck mass. Other chief complaints were pain $(n=28,6.7 \%)$, nasal obstruction $(n=37,8.7 \%)$, epistaxis $(n=8$, $1.8 \%)$, difficulty in hearing $(\mathrm{n}=12,2.7 \%)$ and headache $(\mathrm{n}=10,2.4 \%)$. Nasopharynx was the most common site of development of cancer $(n=193,54.8 \%)$ followed by the tongue $(n=45,12.8 \%)$ and the buccal mucosa $(n=16,4.5 \%)$. Other sites are mentioned in Table 1.

Squamous cell carcinoma was the most prevalent cancer $(n=338,90.1 \%)$ in our study. Adenocarcinoma was the second most common cancer $(\mathrm{n}=16,4.3 \%)$. Fifty five $(16.3 \%)$ subjects had $\mathrm{T} 1$ sized tumor, $89(26.3 \%)$ had $\mathrm{T} 2$ sized tumor, $75(22.2 \%)$ had T3 sized tumor, $111(32.8 \%)$ had T4 sized tumor and $8(2.4 \%)$ had Tx sized tumor. Around $33 \%(\mathrm{n}=111)$ of the subjects had a T4 sized tumor. Amongst those who had a T4 sized tumor, $42(37.8 \%)$ subjects had a tumor, which extended to the base of the skull, larynx $(n=32,28.8 \%)$, pharynx $(n=22,19.8 \%)$, base of the tongue $(n=16,14.4 \%)$, mandible $(n=7,6.3 \%)$ and the maxilla $(n=4,3.6 \%)$. Distant sites, which were involved, were brain and lungs. Around 95\% ( $\mathrm{n}=397)$ of the subjects had a positive nodal involvement at the time of initial diagnosis via FNAB. Ninety-three (28\%) subjects had N0, while, 94 (28.3\%) had N1, 111 (33.4\%) had N2 and 34 $(10.2 \%)$ had N3 nodal involvement. Only twenty-seven (6.4\%) subjects had distant metastasis. In relevance to the histological grading of the cancer, $150(44.5 \%)$ subjects had undifferentiated, $13(3.9 \%)$ subjects had poorly differentiated, $99(29.4 \%)$ subjects had moderately differentiated and $75(22.3 \%)$ subjects had well differentiated cancer as mentioned in Table 1 .

Surgery and radiotherapy was the most common treatment modality $(\mathrm{n}=73,17.4 \%)$ which was utilized for the treatment of cancer in our subjects, followed by neoadjuvant chemotherapy and radiotherapy $(n=64,15.3 \%)$, neoadjuvant chemotherapy and concomittant chemo radiotherapy $(\mathrm{n}=42,10.0 \%)$, radiotherapy $(\mathrm{n}=38,9.1 \%)$ and surgery $(n=30,7.2 \%)$. Rest of the treatment modalities are listed in the Table 1 . Only sixty (14.3\%) subjects encountered complications because of the treatment, which was provided to them. Amongst those who encountered complications, 47 suffered from minor morbidity, 12 suffered from major morbidity and 1 died because of the complications. Of all the subjects in our study only $30(7.1 \%)$ had a recurrence.

Subjects were contacted via telephonic interview. Approximately $77 \%(\mathrm{n}=323)$ of our subjects were alive when they were contacted, while, 23\% ( $n=97)$ had deceased. Cancer was the cause of death of $44(10.5 \%)$ subjects (Table 1). One of the objectives of our study was to look for any association(s) of the studied parameters with the overall survival of our subjects. Following parameters had a statistically significant association with the overall survival of the subjects: Gender $(\mathrm{p}=0.022)$, age $(\mathrm{p}=0.001)$, T4 sized tumor $(\mathrm{p}=0.007), \mathrm{N}$ status $(\mathrm{p}=0.037), \mathrm{M}$ status $(\mathrm{p}=0.001)$, histological grading $(\mathrm{p}=0.043)$, hemoglobin $(\mathrm{p}=0.011)$ and cancer being the cause of death $(\mathrm{p}=0.001)$ (Table 2). In addition to that, Kaplan-Meier survival analysis showed that low haemoglobin levels were associated with poor overall survival outcome of the subjects (Figure 1).

In our study, males comprised of majority of the subjects (63\%), while, more than half of the subjects (54\%) were greater than 50 years of age. This in agreement with the literature as in a cohort study of OSCC patients the male-tofemale ratio was 5.3:1 and the average age at the time of the diagnosis of the patients was 56 years ${ }^{8}$. OSCC is considered as a type of cancer which usually affects men more commonly than women and affects individuals between the fifth and sixth decade of life ${ }^{9}$, although, the male-to-female ratio and the age might vary from region to region and might be dependent on other factors. 
Tobacco is considered as one of the leading causative factors of $\mathrm{OSCC}^{9}$. For instance, a study reported that $72.6 \%$ of the OSCC patients were tobacco users ${ }^{8}$. However, tobacco is used in different forms and the affect of these forms of tobacco might vary on upper aero-digestive tract cancers. In some studies, oral cavity seems to be the least affected site of the entire upper aero-digestive tract by the carcinogenic effect of smoked tobacco, whereas, larynx seems to be the most affected site ${ }^{10,11}$. In contrast, pipe smoking and cigar are considered as a leading cause of development of cancer in the oral cavity ${ }^{11}$. While, chewable tobacco causes a six fold increase in the risk of oral cancer (OR 5.8), as compared to oropharyngeal cancer which has been shown to have a minute risk (OR 1.2) ${ }^{12}$. Surprisingly, in our study only $14.5 \%$ of the subjects had a history of tobacco usage. The presence of different types of cancers in our sample including NPC might be a reason behind the less number of tobacco users in our sample, as other cancers including NPC might have different etiological factors as compared to OSCC. However, numerous patients develop OSCC and NPC who do not have a history of usage or exposure to the established causative factors, which raises an interesting prospect regarding the role of other clinicopathological factors in the development of these cancers.

Around $95 \%(\mathrm{n}=397)$ of the subjects in our study had a positive nodal involvement at the time of initial diagnosis. In some of the previous studies the incidence of occult metastases was $28 \%^{13}, 23 \%^{14}$ and $21 \%{ }^{15}$.

The treatment modalities of OSCC are still the same; surgery being the main treatment modality, it might be the only treatment performed or it might be followed by radiotherapy, radiotherapy might be performed only or in combination with chemotherapy (chemo radiotherapy) which is used as an adjuvant treatment to surgery or as a palliative treatment ${ }^{16}$. Technological advances in surgery, postoperative radiotherapy and concurrent chemo radiotherapy has remarkably improved the survival outcome of OSCC patients during the last decade ${ }^{17,18}$. Surgery and postoperative radiotherapy was the most common treatment modality $(\mathrm{n}=73,17.4 \%)$ in our study, followed by neoadjuvant chemotherapy and radiotherapy $(\mathrm{n}=64,15.3 \%)$, neoadjuvant chemotherapy and concomittant chemo radiotherapy $(\mathrm{n}=42,10.0 \%)$, radiotherapy only $(\mathrm{n}=38,9.1 \%)$ and surgery only $(\mathrm{n}=30,7.2 \%)$.

Of all the subjects in our study only $30(7.1 \%)$ had a recurrence. Recurrence significantly reduces survival in oral cancer patients ${ }^{19}$. Previous studies have shown that numerous OSCC patients die for reasons not related to the cancer itself $f^{20}$. For instance, the main causes of death in a study based on OSCC patients were other malignancies, cardiac, vascular and pulmonary diseases ${ }^{19}$. Our findings are in line with these studies, as cancer was the cause of death of only $10.5 \%$ of the subjects in our study. Although it might be plausible that post treatment complications (as shown in Table 1) might have contributed to the decline in the quality of life of subjects as at least one subject died because of the complications caused by the treatment.

Despite several improvements in the diagnostics and treatment modalities of head and neck cancer, the 5-year survival rate seems to be unaltered over the last two decades ${ }^{6}$. Various clinicopathological parameters might affect the overall survival of such patients. For instance, in our study a statistically significant association was observed between age and overall survival of the subjects $(\mathrm{p}=0.001)$. Numerous studies support our findings that age is significantly associated with disease-specific survival ${ }^{8}$. Some studies showed higher mortality in elderly patients when compared to younger patients ${ }^{21}$, while, others reported higher death rate in younger patients. E.g.; under 40 years of age ${ }^{22}$.

Previous studies suggested primary tumour size as reliable indicator of patient's survival outcome ${ }^{23,24}$. Our study showed a statistically significant relationship $(\mathrm{p}=0.007)$ between large sized tumors. E.g.; T4 stage tumor and overall survival of the subjects.

Although the size of the primary tumour plays a cardinal role in determining the potential of a tumour to metastasize, it is plausible that cancers of minuscule size can metastasise, while, some large cancers never metastasise $^{19}$. Studies have shown nodal involvement as an important predictor of the overall survival of the patients $^{23,24}$, so much so that patients with occult metastasis had 5-fold increased risk of dying from cancer as compared to patients with no occult metastases ${ }^{13}$. The negative effect of occult nodal metastases on the survival outcome of patients is evident by the fact that when patients with occult metastases receive radiotherapy, their disease specific survival is still poorer as compared to patients with pathologically negative necks (DSS rate, 60\% vs. $87 \%)^{13}$. Our findings support the findings of previous studies, as a statistically significant relationship $(\mathrm{p}=0.037)$ was seen between $\mathrm{N}$ status and overall survival of the subjects. 
In addition to the size of the primary tumor and nodal involvement, other indicators of patient's survival outcome are the histological grade and distant metastase ${ }^{25}$. A statistically significant association was observed between $\mathrm{M}$ status ( $\mathrm{p}=0.001$ ), histological grading $(\mathrm{p}=0.043)$, and overall survival of our subjects.

In the current study, low haemoglobin levels were found to be associated with poor survival outcome of the subjects $(\mathrm{p}=0.011)$ (figure 1). Studies have shown anemia to be a prognostic factor for the development of local recurrence $(\mathrm{p}=0.001)$ and ultimately poor prognosis of the patients ${ }^{6}$. Anemia causes resistance to radiation because most likely the haemoglobin level affects tumor response to radiation through the delivery of oxygen to the tumor ${ }^{26}$.

The findings of this study will aid the clinician in diagnosing and treating future cancer patients. This study has identified clinicopathological parameters, which play an important role in determining the survival outcome of oral squamous cell carcinoma and nasopharyngeal carcinoma patients.

Limitations of this study

Following are some of the limitations of this study:

1) Retrospective nature of the study

2) Availability of some of the online data in the form of notes. Extraction of this type of data was time consuming

3) Data for some subjects was missing

4) Some of the patients were referred from other hospitals. Data of those hospitals was not obtainable

One of the major problems which we faced was cleaning and organization of data. Rigorous efforts were made to organize the data for the purpose of statistical analysis

Our work is still in process. We plan to use Kaplan Meier survival analysis to determine the impact of tumor size and nodal involvement on the survival outcome of patients. But a Future research project can focus on some of the parameters which were missing in this study, such as role of molecular markers e.g; HPV 16, HPV 18, EBV, htert gene, VEGF etc. in the prognosis of cancers. In addition to that, some of the important parameters which were lacking in this study such as depth of invasion of the tumor and involvement of margins, neuro-invasion (the online data was missing) can be investigated to see their impact on the prognosis of patients.

\section{Conclusion:-}

This study has identified clinicopathological parameters, which play an important role in determining the survival outcome of oral squamous cell carcinoma and nasopharyngeal carcinoma patients. This study showed a statistically relationship between age, gender, tumor size, nodal involvement, distant metastasis, histological grading, level of hemoglobin and survival outcome of the oral squamous cell carcinoma and nasopharyngeal carcinoma patients. In addition to that, this study also showed the significance of different level of hemoglobin in determining the overall survival outcome of the patients.

Further more studies can focus on some of the parameters which were missing in this study, such as role of molecular markers e.g; HPV 16, HPV 18, EBV, htert gene, VEGF etc. in the prognosis of cancers. In addition to that, some of the important parameters which were lacking in this study such as depth of invasion of the tumor and involvement of margins, neuro-invasion (the online data was missing) can be investigated to see their impact on the prognosis of patients 


\section{References:-}

1. Jemal A, Bray F, Center MM, Ferlay J, Ward E, Forman D. Global cancer statistics. Ca Cancer J Clin 2011; 61:69-90

2. Bagan JV, Scully C (2008) Recent advances in Oral Oncology 2007: epidemiology, aetiopathogenesis, diagnosis and prognostication. Oral Oncol 2008:44(2):103-8

3. Bokemeyer C, Foubert J. Anemia impact and management: focus on patient needs and the use of erythropoietic agents. Semin Oncol. 2004;31:4-11

4. Parvesh K. Impact of anemia in patients with head and neck cancer. TheOncologist 2000;5: (2):13-18

5. Marchal C, Rangeard L, Brunaud C. Anemia impact on treatment of cervical carcinomas. Cancer Radiother. 2005;9(2):87-95

6. Claudia C, Heinz-Theo L, Valentina R, Klaus WG and Astrid L K. An evaluation of the preoperative haemoglobin level as a prognostic factor for oral squamous cell carcinoma. Head \& Neck Oncology 2011;3:35

7. Van AMJ, Hermans J, Boks DE, Leer JW. The prognostic value of hemoglobin and a decrease in hemoglobin during radiotherapy in laryngeal carcinoma. Radiother Oncol 1992;23:229-35

8. I Sawazaki-C, A Rangel, AG Bueno, CF Morais, HM Nagai, RP Kunz, RL Souza, L Rutkauskis, T Salo, A Almangush, RD Coletta. The prognostic value of histopathological grading systems in oral squamous cell carcinomas. Oral Diseases 2015;6:755-761

9. Johnson NW, Jayasekara P, Amarasinghe AA. Squamous cell carcinoma and precursor lesions of the oral cavity: epidemiology and aetiology. Periodontol 2000 2011;57:19-37

10. Applebaum KM, Furniss CS, Zeka A et al. Lack of association of alcohol and tobacco with HPV16-associated head and neck cancer. J Natl Cancer Inst 2007;99:1801-10

11. Znaor A, Brennan P, Gajalakshmi V et al. Independent and combined effects of tobacco smoking, chewing and alcohol drinking on the risk of oral, pharyngeal and esophageal cancers in Indian men. Int $\mathrm{J}$ Cancer 2003;105:681-6

12. Dikshit RP, Kanhere S. Tobacco habits and risk of lung, oropharyngeal and oral cavity cancer: a populationbased case-control study in Bhopal, India.Int J Epidemiol 2000;29:609-14

13. Ganly I, Patel S, Shah J. Early stage squamous cell cancer of the oral tongue-clinicopathologic features affecting outcome. Cancer. 2012 Jan 1;118(1):101-11

14. Pimenta Amaral TM, Da Silva Freire AR, Carvalho AL, Pinto CA, Kowalski LP. Predictive factors of occult metastasis and prognosis of clinical stages I and II squamous cell carcinoma of the tongue and floor of the mouth. Oral Oncol. 2004;40:780-786

15. Kligerman J, Lima RA, Soares JR, et al. Supraomohyoid neck dissection in the treatment of T1/T2 squamous cell carcinoma of the oral cavity. Am J Surg 1994;168:391-394

16. Shah JP, Gil Z: Current concepts in management of oral cancer. Surg Oral Oncol 2009;45:394-401

17. Shiboski CH, Schmidt BL, Jordan RC: Tongue and tonsil carcinoma: increasing trends in the U.S. population ages 20-44 years. Cancer 2005;103:1843-49

18. Amit Moran, Yen Tzu-Chen, Liao Chun-Ta, et al. The International Consortium for Outcome Research (ICOR) in Head and Neck Cancer: Improvement in survival of patients with oral cavity squamous cell carcinoma. An international collaborative study. Cancer 2013;119(24): 4242-48

19. Bloebaum M, Poort LJ, Böckmann RA, Kessler PAWH. Survival after curative surgical treatment for primary oral squamous cell carcinoma. Journal of Cranio-Maxillo-Facial Surgery 2014;1-5

20. Sessions DG, Spector GJ, Lenox J, Parriott S, Haughey B, Chao C, et al: Analysis of treatment results for floorof-mouth cancer. Laryngoscope 2000;110:1764-1772

21. Funk G, Karnell L, Robinson RA, Zhen WK, Trask DK, Hoffman HT. Presentation, treatment, and outcome of oral cavity cancer: a National Cancer Data Base report. Head Neck 2002;24:165-180

22. Sarkaria JN, Harari PM. Oral tongue cancer in young adults less than 40 years of age: rationale for aggressive therapy. Head Neck 1994;16:107-111

23. Kurokawa $\mathrm{H}$, Zhang M, Matsumoto $\mathrm{S}$ et al. The high prognostic value of the histologic grade at the deep invasive front of tongue squamous cell carcinoma. J Oral Pathol Med 2005;34:329-333

24. Huang C-H, Chu S-T, Ger L-P, Hou Y-Y, Sun C-P. Clinicopathologic evaluation of prognostic factors for squamous cell carcinoma of the buccal mucosa. J Chin Med Assoc 2007;70:164-170

25. Shaw RJ, McGlashan G,Woolgar JA, Lowe D, Brown JS, Vaughan ED, et al: Prognostic importance of site in squamous cell carcinoma of the buccal mucosa. Br J Oral Maxillofac Surg 2009;47: 356-359

26. Becker A, Stadler P, Lavey RS, et al. Severe anemia is associated with poor tumor oxygenation in head and neck squamous cell carcinomas. Int J Radiat Oncol Biol Phys 2000, 46:459-466 